\title{
Awareness and Knowledge About Screening Tests for Cervical Cancer in Patients Attending Obstetrics and Gynaecology Out Patient Department at a Tertiary Care Hospital in Lalitpur
}

\author{
Meenu Maharjan and Heera Tuladhar
}

Department of Obstretics and Gynaecology, KIST Medical College, Imadol, Lalitpur, Nepal

\begin{abstract}
Introduction: Cervical cancer is the leading cause of cancer deaths for women worldwide. Early diagnosis of cervical cancer may be done by a simple and cost effective technique of Pap smear. The morbidity and mortality could be significantly reduced with an active cervical cancer screening programme.

Methods: A cross sectional interview based study was done among 200 patients attending Obstetrics and Gynaecology OPD of one of the tertiary care hospital at Lalitpur, to assess the knowledge and awareness of patient regarding screening methods of cervical cancer and its prevention and early detection.

Results: Among all the participants, $76.5 \%(n-153)$ were literate and $23.5 \%(n-47)$ were illiterate. Only $41 \%$ had heard about the Pap test and only $1 \%$ had heard about other methods of screening test like VIA (Visual Inspection with Acetic acid). Only 16\% think that infection of the genital tract and $12.5 \%$ think that multiple partners is the leading cause of cervical cancer. Among them 51\% (n - 102) think that regular screening will prevent cervical cancer. But only 22.5\% (45) had done Pap smear once and $67 \%$ did not know the risk factor of cervical cancer. Only $7 \%$ had heard of HPV vaccination but did not know details about it.

Conclusions: There is very low level of knowledge about cervical cancer, Pap smear and HPV among the participants attending Obstetrics and Gynaecology OPD. For using Pap smear as a preventive method for cervical cancer, it is necessary to inform women about cervical cancer and the Pap smear test. An aggressive campaign with in depth teaching about cervical cancer by media and health care providers is mandatory.
\end{abstract}

Key words: awareness; cervical cancer; knowledge; pap smear; screening test

Correspondence: Meenu Maharjan, Department of Obstretics and Gynaecology, KIST Medical College, Imadol, Lalitpur, Nepal. E-mail: meenumaharjan@gmail.com

DOI: $\underline{\text { http://dx.doi.org/10.3126/mjsbh.v17i2.20019 }}$

Submitted on: 2018-05-27

Accepted on: 2018-06-29 


\section{INTRODUCTION}

Worldwide, the leading cause of cancer deaths for women is cervical cancer. The incidence of cervical cancer is around 510,000 new cases annually worldwide and accounting for about 288,000 deaths. ${ }^{1}$ The bulk of deaths of around $85 \%$ are reported from low and middle income countries. ${ }^{2}$ As per $\mathrm{WHO}$, the crude incidence rate of cervical cancer in Nepal is approximately 24.2 per 100,000 women per year, with 3,504 new cases annually and leading to about 1,872 deaths annually. ${ }^{3}$

The introduction of different screening tests for cervical cancer has led to significant decrease in morbidity and mortality from the cervical cancer. In our country, screening tests have been introduced for early detection of cervical cancer. For instance, Papanicolaou (Pap) smear screening is the gold standard method to detect early cervical cancer. ${ }^{4}$ Although the Pap test is the primary method of screening, due to the lack of proper infrastructure, human resources as well as finances, its feasibility among the general population is often questioned and perhaps inadequate. ${ }^{4-6}$ More recently, visual inspection with acetic acid (VIA) is the alternative screening test which is more convenient, affordable and accurate method of screening for cervical cancer. ${ }^{7-9}$

Generally in countries where Pap smear screening is being used as a routine test, the females who have had sex are recommended to get regular Pap smear testing. Different guidelines advise the frequency of testing from every three to five years. When results are abnormal or suspicious, repeat test may be done in six to 12 months. ${ }^{10}$

The basic lack of knowledge and awareness about Pap smear as a screening program for cervical cancer in most resource limited countries has led to a higher incidence of cervical cancer. Thus, one of the most important strategy for prevention of cervical cancer would be to increase awareness and knowledge among women regarding Pap smear. ${ }^{11}$

\section{METHODS}

A cross-sectional interview based study was done among 200 patients attending the Obstetrics and gynaecology outpatient clinics of tertiary care teaching hospital located at Imadol, Lalitpur. Each participant received verbal explanation about the objectives of the study and informed verbal consent was taken before starting the interview. Survey questions were originally prepared in English language and translated into Nepali.

The survey composed of socio-demographic data, namely: age, marital status and address, level of education and profession of both the partners. Then next section composed of awareness of the cervical cancer and its screening test, namely: have you heard of Pap smear or other screening tests, have you done it? The next section comprised of knowledge of the cervical cancer and screening test, namely: Do you know the risk factor or cervical cancer, can regular screening prevent cervical cancer, and do you know about the HPV vaccination?

\section{RESULTS}

As shown in table 1, maximum number of participants $(61 \%)$ were at the age group of 21 to 30 years. All the study participants were married females of age $>/=18$ years. The mean age of the participants was $29.92+/-1.46$ years. Among the participants, $72(36 \%)$ were multipara and 58 (29\%) were nulliparous. As shown in table 2, mean age of marriage was $28.91+/-7.38$ years. Among them, most of the participants were monogamy (196), only four were polygamy. Among them the number of participants living with their husband was 194 (97\%).

Regarding the age of marriage, maximum numbers of the participants were married at the age below 20 
Table 1. Sociodemographic characteristics of the participants

\begin{tabular}{|c|r|}
\hline Characteristics & Frequency (\%) \\
\hline Age groups (Yrs) & $16(2)$ \\
\hline $10-20$ & $122(61)$ \\
\hline $21-30$ & $43(21.5)$ \\
\hline $31-40$ & $18(9)$ \\
\hline $41-50$ & $1(0.5)$ \\
\hline$>50$ & \\
\hline Marital status & $194(97)$ \\
\hline Married & $3(1.5)$ \\
\hline Separated & $3(1.5)$ \\
\hline Widowed & \\
\hline Types of marriage & $196(98)$ \\
\hline Monogamy & $4(2)$ \\
\hline Polygamy & \\
\hline Education level & $54(23.5)$ \\
\hline Illiterate & $53(21.5)$ \\
\hline Primary & $56(38)$ \\
\hline Secondary & \\
\hline Higher & \\
\hline
\end{tabular}

years (134), below 30 years (63) and below 40 years (3). Among them 111 participants were not using any means of contraception and 89 were using long term and short term methods of contraception. Regarding the number of children, 193 (96.5\%) had less than four children as shown in table 2.

Among the 200 participants, only 47 (23.5\%) were illiterate and other $153(76.5 \%)$ were literate at some level. Maximum number, 58 (28\%) had higher level of study whereas 97 (48.5\%) had primary and secondary level of study as shown in table 1. Maximum number of them were housewife 114 (57\%), 45 (22.5\%) were self employed and 28 $(14 \%)$ were service holder, only three (1.5\%) were staff nurse as shown in fig 1 . Regarding risk factors
Table 2. Sexual and reproductive history

\begin{tabular}{|c|r|}
\hline \multicolumn{1}{|l|}{ Variables } & Frequency (\%) \\
\hline Age at marriage (Yrs) & $134(67.0 \%)$ \\
\hline $10-20$ & $63(31.5 \%)$ \\
\hline $21-30$ & $3(1.5 \%)$ \\
\hline $31-40$ & $196(98.0 \%)$ \\
\hline Number of sexual partner (s) & $4(2.0 \%)$ \\
\hline 1 & $193(96.5 \%)$ \\
\hline$>1$ & $7(6.5 \%)$ \\
\hline $0-4$ & \\
\hline Number of children ever had & \\
\hline
\end{tabular}

of cervical cancer, maximum numbers 134 (67\%) did not know about the risk factors of the cervical cancer. Only $25(12.5 \%)$ said that infection of the genital tract will lead to cervical cancer. Maximum number $(168,84 \%)$ did not know that young age at first intercourse is a risk factor and only 14 (7\%), $18(9 \%)$ and seven (3.5\%) said that early marriage, multiple partners and smoking respectively will lead to cervical cancer (Fig 2).

Regarding the diagnosis and screening of the cervical cancer, 82 (41\%) had heard about the Pap smear and only two (1\%) had heard about the VIA. Among the participants 102 (51\%) believed that regular screening can prevent cervical cancer, only $15(7.5 \%)$ did not know about that regular screening can prevent cervical cancer. Only seven (3.5\%) had heard of HPV Vaccination but did not know the detail about it. Among 82 patients who had heard of Pap smear, only 45 (22.5\%) had done Pap smear and two (1\%) had done VIA (Table 3).

\section{DISCUSSION}

Non-communicable diseases are emerging as an important health problem even in developing countries because of the changes in the life styles and demographic profiles. Timely implementation 


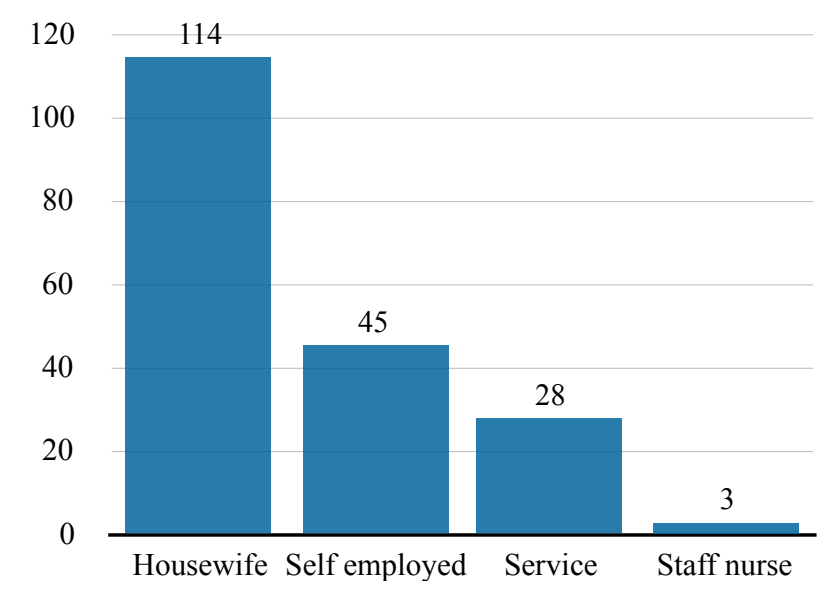

Fig 1. Occupations of the participants

Table 3. Awareness of cervical cancer and screening service

\begin{tabular}{|c|c|}
\hline Variables & Frequency (\%) \\
\hline \multicolumn{2}{|l|}{$\begin{array}{l}\text { Regular screening prevent } \\
\text { cervical cancer }\end{array}$} \\
\hline Yes & $102(51)$ \\
\hline No & $15(7.5)$ \\
\hline Don’t know & $83(41.5)$ \\
\hline \multicolumn{2}{|l|}{ Heard of Pap smear } \\
\hline Yes & $82(41)$ \\
\hline No & $118(59)$ \\
\hline \multicolumn{2}{|l|}{ Had Pap smear } \\
\hline Yes & $45(22.5)$ \\
\hline No & $155(77.5)$ \\
\hline \multicolumn{2}{|l|}{ Heard of VIA/VILI } \\
\hline Yes & $2(1)$ \\
\hline No & $198(99)$ \\
\hline \multicolumn{2}{|l|}{ Done VIA/VILI } \\
\hline Yes & $2(1)$ \\
\hline No & $198(99)$ \\
\hline \multicolumn{2}{|l|}{ Heard of HPV-vaccination } \\
\hline Yes & $7(3.5)$ \\
\hline No & $193(96.5)$ \\
\hline
\end{tabular}

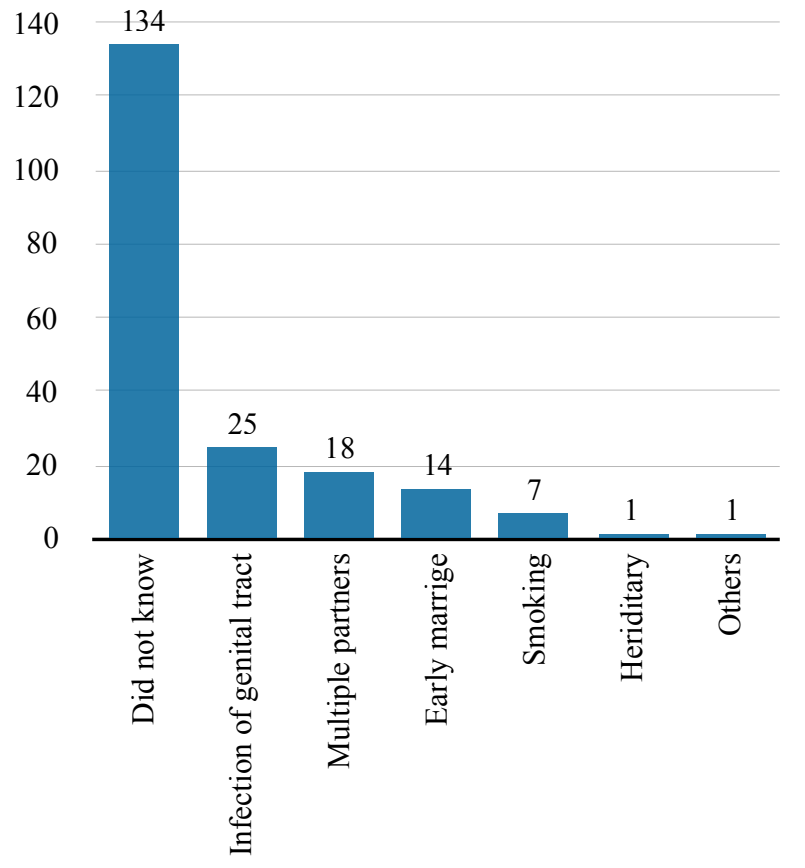

Fig 2. Knowledge of the risk factors

of appropriate control programs should be considered before the assumed epidemic propagation occurs. As a non communicable disease, cancer has been a major cause of morbidity and mortality all over the world.

Ideally, screening test should be minimally invasive, easy to perform, acceptable to the subject as well as cost-effective. It should diagnose the disease process in its pre-invasive or early invasive state so that the disease may be easily treatable and curable. As per WHO criteria, cervical cancer is thus probably the only gynaecological cancer which may be used for screening program. ${ }^{12}$ In our study, maximum number of patients were the age group of 20 to 39 years which is similar to another study by Maruf $\mathrm{R}$ et al. ${ }^{13}$

Despite the vast majority of respondent being educated women $(76.5 \%)$, it is worrisome that around $59 \%$ of them were not aware of the Pap smear screening test and $77.5 \%$ had not done it before. Our results are similar to a study done by Khudairi $\mathrm{H}$ et al. ${ }^{14}$ These results hint towards serious flaws or strategic failure on behalf of the 
awareness efforts implemented by the Ministry of Health, healthcare facilities, physicians as well as public media. Majority of our participants were highly educated women which is above the average education level of the general population of a developing third-world country. Hence the awareness level could be actually even more dismal than what has been present in the study. It has been well documented that there is a direct correlation between the low level of education and low level of awareness of Pap smear. ${ }^{15}$

Screening behaviour is affected by the perception of one's susceptibility to cervical cancer. Many women believed it was unnecessary for them to have a Pap smear test done as they expressed a lack of personal susceptibility to cervical cancer. ${ }^{16}$ This is in harmony with a study which suggested that women's cervical screening behaviour is predicted by their susceptibility to cervical cancer. ${ }^{17}$ Thus, more efforts should focus on informing women of their susceptibility to cervical cancer. This perception of vulnerability to the disease would motivate women for active and regular screening by Pap smear. This would help pick up cervical cancer at the pre-cancerous stage and enable to initiate early treatment and thus help in prevention of cancer development and spread. Rather than depending upon health care provider's recommendation for Pap smear screening, women should be made more responsible for their own health and be encouraged to be active participants in the screening programmes.

The study done in Ogbomoso, Nigeria ${ }^{18}$ found that awareness was $28.4 \%$ which is lower than our study i.e, $41 \%$ yet it is lower than the developed countries. This implied that the impact of current efforts at increasing awareness about cervical cancer is yet to have positive effects. Thus, there is urgent need for a review of these approaches, identifying the challenges associated with the low awareness and finding ways of overcoming them. The same study ${ }^{18}$ stated that age of first sexual intercourse was found to maximum at the age of 20 to 29 years $(69.9 \%)$ and below 20 years were $18.2 \%$ whereas in our study maximum number of participants were less than 20 years (67\%). This clearly stated that the maximum number of women participated in our study were in high risk of developing cervical cancer. Number of children less than four was $96.5 \%$ which is similar as study done in Nigeria.

\section{CONCLUSIONS}

Pap smear could significantly reduce the morbidity and mortality caused by cancer of uterine cervix provided it is used as active cervical smear screening (PAP smear) programme. There is inadequate awareness of cervical cancer and poor knowledge of its risk factors. Women lack knowledge about Pap smear screening and followup services. The poor knowledge/awareness of the disease has also led to inadequate practice towards prevention. It is a major challenge in resource limited set up to formulate an easily available screening programme to cover a large section of society. It is recommended that religious and culture based education should be promoted. There should be messages which are locally understood to increase the awareness of the disease. When required, women should be motivated to get tested at once and follow-up should be easily available. For this, training of medical and paramedical staffs stating from primary health centre level up to the highest level should be done. With this, a cost effective screening method such as Pap smear screening for cervical cancer can be developed and fostered.

The uptake of cervical cancer screening was very low among the general population. The challenge to improve uptake of screening test was lack of awareness and knowledge about cervical cancer 
and its preventive measures. Therefore, it is very important to concentrate more effort on increasing awareness and enhancing the knowledge of women about cervical cancer and screening to step up the campaign for the control of cervical cancer in Nepal.

To cite this article: Maharjan M, Tuladhar H. Awareness and knowledge about screening tests for cervical cancer in patients attending obstetrics and gynaecology out patient department at a tertiary care hospital in Lalitpur. MJSBH. 2018;17(2):12-8.

Conflict of Interest: None declared

\section{REFERENCES}

1. Sankaranarayanan R, Ferlay J. Worldwide burden of gynaecological cancer: the size of the problem. Best pract Res Clin Obstet Gynaecol. 2006;20:207-25.

DOI: https://doi.org/10.1016/j.bpobgyn.2005.10.007～PMid:16359925

2. World Health Organisation. Comprehensive cervical cancer prevention and control: a healthier future for girls and women. Geneva, Switzerland: World Health Organisation Press; 2013.

3. Information Center on HPV and Cervical Cancer. Human papillomavirus and related cancers, fact sheet 2013.

4. Pradhan P. Prevention of carcinoma cervix: role of Pap smear screening. Nepal Med Coll J. 2003: 5:82-6. PMid:15024772

5. Sherpa AT. Time for an Organized Cervical Cancer Screening in Bharatpur, Nepal. Master's thesis. Oslo, Norway: University of Oslo; 2007.

6. Dixit S, Singh M. Cervical cancer in Nepaliwomen. October 31, 2010.

7. Dhaubhadel P, Vaidya A, Choudhary P. Early detection of precursors of cervical cancer with cervical cytology and visual inspection of cervix with acetic acid. JNMA J Nepal Med Assoc. 2008;47:71-6. PMid:18709035

8. Satyal K. Cervical cancer screening behavior among Nepalese women. PhD dissertation. Fairfax, VA, USA: George Mason University; 2013.

9. Khan S, Jha R, Pant P. Accuracy of cytology, visual inspection with acetic acid or lugol's iodine in cervical cancer screening. N J Obstet Gynaecol. 2007;2:48-53.

DOI: http://dx.doi.org/10.3126/njog.v2i2.1455

10. Saslow D, Solomon D, Lawson H, Killackey M, Kulasingam S, Cain J, et al. American Cancer Society for Colposcopy and Cervical Pathology, and American Society for Clinical Pathology Screening Guidelines for the Prevention and Early detection of cervical cancer. Journal of Lower Genital Tract Disease. 2012;16(3):175-204. 
11. Cronjé HS. Screening for cervical cancer in the developing world. Best practice and research Clinical obstetrics and gynaecology. 2005 Aug;19(4):517-29.

DOI: https://doi.org/10.1016/j.bpobgyn.2005.02.005～PMid:16150391

12. Kerkar RA, Kulkarni YV. Screening for cervical cancer: an overview. J Obstet Gynecol India. 2006;56(2):115-22.

DOI: http://www.jogi.co.in/mar_apr_2006/02_ra_screening.pdf

13. Maruf R, Ahmed ST, Islam ST. Cervical PAP Smears in Jahurul Islam Medical College Hospital Experience of 558 cases. 2017;50-3.

DOI: http://www.ijarbs.com/pdfcopy/dec2016/ijarbs11.pdf

14. Al Khudairi H, Abu-Zaid A, Alomar O, Salem H. Public Awareness and Knowledge of Pap Smear as a Screening Test for Cervical Cancer among Saudi Population in Riyadh City. Cureus. 2017 Jan;9(1).

DOI 10.7759/cureus.984.

15. Roberts AA, Ayankogbe OO, Osisanya TF, Bamgbala AO, Ajekigbe AT, Olatunji BS, et al. Knowledge of cervical cancer risk factors among refugee women in Oru camp. Niger Med Pract. 2004; 46(4):67-70.

DOI: https://doi.org/10.4314/nmp.v46i4.28730

16. Wong L P, Wong Y L, Low W Y, Khoo E M, Shuib R. Knowledge and awareness of cervical cancer and screening among Malaysian women who have never had a Pap smear: a qualitative study. Singapore Med J 2009; 50(1):49-53.

PMid:19224084

17. Hill D, Gardner G, Rassaby J. Factors predisposing women to take precautions against breast and cervical cancer. J Appl Soc Psychol. 1985;15:59-79.

DOI: https://doi.org/10.1111/j.1559-1816.1985.tb00894.x

18. Abiodun AB, Oluwasola TAO, Durodola AO, Ajani MA, Abiodun AD, Adeomi AA. Awareness and perception of risk for cervical cancer among women in Ogbomoso, Nigeria. Trop J Obstet Gynaecol. 2017;34:218-23.

DOI: https://doi.org/10.4103/TJOG.TJOG_56_16 